\title{
Direct comparison of polyethylene wear in cemented and uncemented acetabular cups
}

\author{
Håvard Bjerkholt • Øystein Høvik • \\ Olav Reikerås
}

Received: 21 January 2010/Accepted: 9 August 2010/Published online: 2 September 2010

(c) The Author(s) 2010. This article is published with open access at Springerlink.com

\begin{abstract}
Background It has been indicated that, in the long term, the rate of wear and the degree of osteolysis observed with uncemented acetabular components are greater than those associated with cemented cups, but most studies which compare the wear characteristics of cementless with cemented cups have used historical controls. We report a direct comparison of wear of a cemented and an uncemented cup with similar design, polyethylene, and sterilization method.

Materials and methods The study cohort includes 92 patients who were operated in 1997 with primary total hip replacement and have been followed for a period of 9-10 years. All patients were operated by posterolateral approach. In patients 70 years or older we used a cemented cup, in those 60 years or younger we used an uncemented cup, and in patients between 60 and 70 years we used either a cemented or uncemented cup as decided by the surgeon. At follow-up, radiographic imaging was obtained as standard anterioposterior view of the pelvis, and mean wear was determined as described by Livermore et al.

Results The overall wear of the cemented acetabular components was $1.07 \pm 0.78 \mathrm{~mm}$, and that of the uncemented cups was $1.18 \pm 0.61 \mathrm{~mm}(P=0.529)$. Wear was significantly associated with male sex $(P=0.003)$, younger age $(P=0.003)$, and degree of inclination
\end{abstract}

\footnotetext{
H. Bjerkholt · Ø. Høvik

Department of Orthopaedic Surgery,

Lovisenberg Deaconal Hospital, Oslo, Norway

O. Reikerås $(\square)$

Faculty Division Rikshospitalet,

University of Oslo, 0027 Oslo, Norway

e-mail: olav.reikeras@ rikshospitalet.no
}

$(P<0.001)$, but wear was not significantly associated with cemented versus uncemented cup $(P=0.437)$.

Conclusion Our findings in this 9-10-year follow-up study suggest that cementless cups wear no more than cemented cups of similar design.

Keywords Hip · Polyethylene $\cdot$ Prosthesis - Wear

\section{Introduction}

In total hip arthroplasty, polyethylene debris is mainly responsible for the development of osteolysis with subsequent loss of bone stock and implant fixation [1-3]. In the early 1980s several reports showed that, in the long term, the rate of wear and the degree of osteolysis observed with uncemented cups were greater than those associated with cemented components [4-11], but in one study this could not be proved [12]. As no studies have reported direct comparison of long-term results of cemented versus uncemented acetabular components, the question of whether a cemented all-polyethylene cup has better behavior than an uncemented one has not been fully clarified. This study was undertaken to compare wear of a cemented and an uncemented cup with similar design, polyethylene, and sterilization method. Our hypothesis was that there is no difference in the rate of wear of polyethylene between a cemented and an uncemented cup with similar design, polyethylene, and sterilization method.

\section{Materials and methods}

The study was approved by the local ethical committee and performed in accordance with the ethical standards of the 
1964 Declaration of Helsinki as revised in 2000. All patients gave informed consent. The study cohort included 92 patients who were operated in 1997 with primary total hip replacement (THR) due to osteoarthritis and have been followed for a period of 9-10 years. All patients were operated by posterolateral approach. In patients 70 years or older we used a cemented cup, in those 60 years or younger we used an uncemented cup, and in patients between 70 and 60 years we used either a cemented or uncemented cup as decided by the surgeon. The cemented cup was an all-polyethylene UHMWPE Reflexion Cup (Smith \& Nephew Richards Inc. Memphis, TN, USA), and the uncemented cup was a TI-6AL4V Reflexion Porous Acetabular Shell with a UHMWPE Reflexion Microstable Acetabular Liner (Smith \& Nephew Richards Inc. Memphis, TN, USA). The polyethylene was machined using ram extrusion and sterilized with ethylene oxide (EtO). In all patients we used a cemented Co-Cr Biofit Femoral Component (Smith \& Nephew Richards Inc., Memphis, TN, USA) and a 28-mm Co-Cr Universal Head (Smith \& Nephew Richards Inc., Memphis, TN, USA).

In the cemented group there were 12 males and 50 females, and in the uncemented group there were 10 males and 20 females $(P=0.141)$. The age of the patients in the cemented group was $72 \pm 6$ [95\% confidence interval (CI) 71-73; range 60-84] years, and the age of the patients in the uncemented group was $64 \pm 2$ (95\% CI 63-66; range 57-70) years $(P<0.001)$. The size of the cemented cups was $53 \pm 2(95 \%$ CI 52-54), and the size of the uncemented cups was $54 \pm 3(95 \%$ CI 53-55) $(P=0.017)$. The inclination of the cemented cups was $50 \pm 9^{\circ}(95 \% \mathrm{CI}$ $\left.48-52^{\circ}\right)$, while the inclination of the uncemented cups was $53 \pm 8^{\circ}\left(95 \%\right.$ CI $\left.48-59^{\circ}\right)(P=0.123)$.

At follow-up, radiographic imaging was obtained as standard anterioposterior view of the pelvis, with the beam centered at the symphysis pubis and the hips corrected for rotation. All measurements were corrected for magnification determined in each radiograph by measuring the diameter of the known implanted femoral head. The images were reviewed by two observers, and the mean wear was determined as described by Livermore et al. [13].

Wear was analyzed in a multivariate model that included sex, age, cup size (mm), and cup inclination (SPSS Inc., Chicago, IL, USA). Data are presented as mean \pm standard deviation and $95 \%$ confidence interval (CI). Continuous data were compared using Student's $t$-test, and chi-square test was used to compare frequencies. The level of significance was set to $P<0.05$.

\section{Results}

The overall wear of the cemented acetabular components was $1.07 \pm 0.78(95 \%$ CI $0.89-1.26) \mathrm{mm}$, and wear of the uncemented cups was $1.18 \pm 0.61$ (95\% CI 0.91-1.44) $\mathrm{mm}(P=0.529)$. Wear was significantly associated with male sex $(P=0.003)$, younger age $(P=0.003)$, and degree of inclination $(P<0.001)$, but wear was not significantly associated with cemented versus uncemented cups $(P=0.437)$ or cup size $(P=0.451)$.

\section{Discussion}

This study was undertaken to determine the wear of a cemented versus an uncemented acetabular component with the same design, fabrication, and polyethylene. Our results support our hypothesis that wear rates are equal during a period of 9-10 years. We determined wear using the Livermore technique [13], which has accuracy similar to other manual and computerized wear measurement methods $[14,15]$. The complexities of wear measurements and the implications of out-of-plane wear have been extensively discussed in the literature [16-18], but in general the repeatability is acceptable [19].

The major weakness of our study is that it is not randomized. Also, difference in age between the two groups is a clear confounding variable. Younger age was significantly associated with wear, and older age in our patients with a cemented cup is in contradiction to previous reports that a cemented all-polyethylene cup has better behavior than an uncemented in terms of wear.

The strength of our study includes strict patient inclusion criteria, all with a diagnosis of osteoarthritis, undergoing surgery in the same hospital by the same surgeons, with the same surgical technique, and all with the same cemented stem and 28-mm chromium cobalt head. All patients have the same length of follow-up, and also our focus directly on wear of the acetabular component can be considered a strength of the study.

In both the cemented and uncemented components the polyethylene was machined using ram extrusion and sterilized with ethylene oxide (EtO). There are indications that PE components produced using molding provide for less wear compared with extruded components [20], but a main factor responsible for wear of UHMWPE in hip replacements is oxidative degradation, which degrades its mechanical properties [21]. Oxidation is strictly correlated with sterilization using high-energy radiation in air $(\gamma$ radiation or an electron beam with dose of 25-40 kGy). UHMWPE components sterilized with ethylene oxide (EtO) do not oxidize. Our results, therefore, should be restricted to these methods of production and sterilization of PE.

The modularity of the uncemented acetabular component and its relation with polyethylene wear have been matters of concern. There has been a suggestion that 
modularity of an uncemented acetabular component contributes to increase of wear [11, 22-24], and Hernandez et al. [5] conjectured that this may be due to the fact that the cement absorbs some of the stresses and thus reduces the forces on polyethylene. It has been shown that load transfer to cortical and cancellous bone is different after cemented versus uncemented hip prosthesis [25].

The use of an uncemented porous socket in combination with a cemented femoral component was recommended for primary hip replacement in the 1990s [26] and generally in younger age groups. Our patients with an uncemented cup were younger than those with a cemented cup. Multivariate analyses have shown a significant increase in rate of polyethylene wear in patients with excellent Harris hip score and younger age [27], and increased rate of wear has been likely related to level of activity in younger patients. Accordingly, we found a significant association between younger age and wear in our patients. With an assumed higher activity level in the uncemented group, they should have been expected to have higher wear. This underlines that wear of the uncemented cups at least was not higher than that of the cemented cups.

Furthermore, we found an association between male sex and wear, and although not significant, there were relatively more males than females in the uncemented group as compared with the cemented group. And third, there was a significant association between degree of inclination and wear, and the uncemented cups were inserted with higher inclination than the cemented cups. These facts support the notion that uncemented cups do not wear more than cemented cups in the long run.

In conclusion, we performed a direct comparison of long-term wear of cemented versus uncemented types of acetabular component, and there were no significant differences in the rate of wear.

\section{Conflict of interest None.}

Open Access This article is distributed under the terms of the Creative Commons Attribution Noncommercial License which permits any noncommercial use, distribution, and reproduction in any medium, provided the original author(s) and source are credited.

\section{References}

1. Dumbleton JH, Manley MT, Edidin AA (2002) A literature review of the association between wear and osteolysis in total hip arthroplasty. J Arthroplasty 17:649-661

2. Sochart DH (1999) Relationship of acetabular wear to osteolysis and loosening in total hip arthroplasty. Clin Orthop Relat Res 363:135-150

3. Orishimo KF, Claus AM, Sychterz CJ, Engh CA (2003) Relationship between polyethylene wear and osteolysis in hips with a second-generation porous-coated cementless cup after seven years of follow-up. J Bone Joint Surg Am 85:1095-1099

4. Berry DJ, Barnes RD, Scott ME (1994) Catastrophic failure of the polyethylene liner of uncemented acetabular components. J Bone Joint Surg Br 76:575-681

5. Hernandez JR, Keating EM, Faris PM, Meding JB, Ritter MA (1994) Polyethylene wear in uncemented acetabular components. J Bone Joint Surg Br 76:263-266

6. Huk O, Bansal M, Betts F, Rimnac CM, Lieberman JR, Huo MH, Salvati EA (1994) Polyethylene and metal debris generated by non-articulating surfaces of modular acetabular components. J Bone Joint Surg Br 76:568-574

7. Nashed RS, Becker DA, Gustilo RB (1995) Are cementless acetabular components the cause of excess wear and osteolysis in total hip arthroplasty? Clin Orthop Relat Res 317:1928

8. Maloney WJ, Galante JO, Anderson M, Goldberg V, Harris WH, Jacobs J, Kraay M, Lachiewicz P, Rubash HE, Schutzer S, Woolson ST (1999) Fixation, polyethylene wear, and pelvic osteolysis in primary total hip replacement. Clin Orthop Relat Res 369:157-164

9. Della VCJ, Berger RA, Shott S (2004) Primary total hip arthroplasty with a porous-coated acetabular component. A concise follow-up of a previous report. J Bone Joint Surg Am 86:12171223

10. Gaffey JL, Callaghan JJ, Pedersen DR, Goetz DD, Sullivan PM, Johnston RC (2000) Cementless acetabular fixation at fifteen years. A comparison with the same surgeon's results following acetabular fixation with cement. J Bone Joint Surg Am 86:257261

11. McCombe P, Williams SA (2004) A comparison of polyethylene wear rates between cemented and cementless cups. A prospective, randomized trial. J Bone Joint Surg Br 86:344-349

12. Onsten A, Carlsson S, Besjakov J (1998) Wear in uncemented porous and cemented polyethylene sockets. A randomized, radiosterometric study. J Bone Joint Surg Br 80:345-349

13. Livermore J, Ilstrup D, Morrey B (1990) Effect of femoral head size on wear of the polyethylene acetabular component. J Bone Joint Surg Am 72:518-523

14. Ebramzadeh E, Schmoelz W, Lattuada F (2002) Assessment of clinical accuracy of measurement methods for THR polyethylene wear. Presented at the annual meeting of the American academy of orthopaedic surgeons, Dallas, TX, February

15. Barrack RL, Lavernia C, Szuszczewicz ES, Sawhney J (2001) Radiographic wear measurements in a cementless metal-backed modular cobalt-chromium acetabular component. J Arthroplasty $16: 820-828$

16. Sporer SM, Callaghan JJ, Olejniczak JP, Goetz DD, Johnston RC (1998) Hybrid total hip arthroplasty in patients under the age of fifty: a five- to ten-year follow-up. J Arthroplasty 13:485-491

17. Tompkins GS, Jacobs JJ, Kull LR, Rosenberg AG, Galante JO (1997) Primary total hip arthroplasty with a porous-coated acetabular component. Seven-to-ten year results. J Bone Joint Surg Am 79:169-176

18. Berger RA, Jacobs JJ, Quigley LR, Rosenberg AG, Galante JO (1997) Primary cementless acetabular reconstruction in patients younger than 50 years old. 7- to 11-year results. Clin Orthop Relat Res 344:216-226

19. Dowdy PA, Rorabeck CH, Bourne RB (1997) Uncemented total hip arthroplasty in patients 50 years of age or younger. J Arthroplasty 12:853-862

20. Faris P, Ritter M, Pierce AL, Davis K, Faris G (2006) Polyethylene sterilization and production affects wear in total hip arthroplasties. Clin Orthop Relat Res 453:305-308

21. Brach del Prever EM, Bistolfi A, Bracco P, Costa L (2009) UHMWPE for arthroplasty: past or future. J Orthop Traumatol $10: 1-8$ 
22. Huk OL, Bansal M, Betts F, Rimnac CM, Lieberman JR, Huo MH, Salvati EA (1994) Polyethylene and metal debris generated by non-articulating surfaces of modular acetabular components. J Bone Joint Surg Br 76:568-574

23. Chen PC, Mead EH, Pinto JG, Colwell CW Jr (1995) Polyethylene wear debris in modular acetabular prostheses. Clin Orthop Relat Res 317:44-56

24. Fehring TK, Smith SE, Braun ER, Mobley C, Wang PL, Griffin WL (1999) Motion at themodular acetabular shell and liner interface. Clin Orthop Relat Res 367:306-314

25. Mueller LA, Schmidt R, Ehrmann C, Nowak TE, Kress A, Forst R, Pfander D (2009) Modes of periacetabular load transfer to cortical and cancellous bone after cemented versus uncemented total hip arthroplasty: a prospective study using computedtomography-assisted osteodensitometry. J Orthop Res 27:176-182

26. Total Hip Replacement (1994) NIH Consensus Statement 12:1-31

27. Kurtz SM, Ochoa JA, White CV, Srivastav S, Cournoyer J (1998) Backside nonconformity and locking restraints affect liner/shell load transfer mechanisms and relative motion in modular acetabular components for total hip replacement. J Biomech $31: 431-437$ 